\title{
O SEISCENTISTA CAMILLO BALDI E A PESSOA DO ESCRITOR DE CARTAS PRIVADAS
}

\author{
Edmir Míssio
}

E quem quer que ouça dizer que da leitura de uma carta privada seja possível conhecer os pensamentos, os costumes e as disposições do escritor, ou rirá ou, se carece de arrogância, ficará bastante maravilhado.

BALDI. Come da una Lettera Missiva..., p. 8-9.

Camillo Baldi (1550-1637) foi um notório professor de filosofia e medicina teórica na Universidade de Bolonha, e creio que não há como não deixar de ver nas palavras acima um eco da defesa que Hipócrates (séc. V-IV a.C.) havia feito em seu tratado A Arte Médica, como se pode ler aqui: "aquele que maldiz as artes [...] me parece dar menos provas de saber e atração pela ciência do que de jactância, ou de uma maldade natural, ou de desprezo pelas artes" (HIPÓCRATES, séc. V/1823, p. 295-296).

Em seu opúsculo Come da una lettera missiva si conoscano la natura e qualità dello scrittore (Como de uma carta missiva se conheçam a natureza e a qualidade do escritor), como veremos, o professor bolonhês também propõe uma arte com base em indícios, tal como a medicina, que nas alterações do corpo vê os sinais para o reconhecimento da doença.

${ }^{1}$ Este é um dos textos produzidos a partir da minha pesquisa sobre a retórica dos secretários de palácio nos séculos XVI eXVII, a qual foi realizada em meu pós-doutorado junto ao DLCV-USP, sob a supervisão do prof. João Adolfo Hansen e o patrocínio da Fapesp. 
Além dessa obra, o interesse pela produção e interpretação das cartas levou Baldi a produzir mais dois textos sobre o tema, e os três foram editados conjuntamente pela primeira vez em 1622, em Carpi, apresso Girolamo Vaschieri. O mais extenso e o primeiro dos três é Alcune considerationi sopra una lettera d'Anton' Perez scrita al duque di Lerma circa al modo di conservarsi in gratia del suo Signore, e contém uma breve carta do famoso secretário espanhol Antonio Perez, a qual é comentada período por período, seja em termos do modo de exprimir-se pelas palavras e metáforas usadas, seja em termos da lógica ou não da argumentação provida ali. $\mathrm{O}$ mais curto e o último dos três intitula-se Avvertimenti intorno allo scrivere bene le lettere missive, e continua a lição do pseudo-Demétrio sobre a carta entre amigos, a pedir linguagem clara e não oratória, defendida no breve tratado Come da una lettera...

O interesse de Baldi pela interpretação da escrita das cartas coadunase com outro, o da Fisiognômica pseudoaristotélica, da qual ele próprio havia feito um extenso comentário editado em 1621, recordando-se com o crítico hodierno Armando Petrucci que a fisiognômica era uma "ciência que presumia reconstruir índoles e propensões dos homens a partir de suas características físicas" (apud BALDI, 1622/1992, p.XII). Alessandro Fontana, por sua vez, aponta que os fundamentos da fisiognômica se deveriam a Hipócrates, uma vez que a medicina antiga baseava-se na "correspondência simétrica e recíproca entre o físico e o moral, a alma e o corpo" (apud BALDI, 1622/1993, p.31). Segundo o próprio autor da Fisiognômica (806a28), essa reconstrução da alma se daria com base nos movimentos e na aparência: "atitudes, carnação, traços do rosto, cabelos, pelos, voz, carne, diversas partes e forma do corpo”.

Um pressuposto aristotélico dessa pretensão de conhecimento do interno (pensamento/sentimento) pelo externo (neste caso, pelo movimento apenas) pode ser plausivelmente divisado no Da Alma, Peri psiquê (I, III, 406azo-406b), onde podemos ler: "uma vez que a alma pode ser considerada motor do corpo, é razoável supor que compartilhe com ele os mesmos movimentos; e se assim for, é certo afirmar inversamente que a alma tem os mesmos movimentos que o corpo". Quando vamos à Retórica do mesmo filósofo, vemos que, enquanto instrumento da política, isto é, da organização da cidade (pólis), o uso da técnica do discurso público entende mover os corpos e as mentes da audiência, imprimir ações, sentimentos e pensamentos por meio da ação das palavras e dos gestos do orador sobre a alma (psiquê) dos espectadores.

O tratado de Baldi surpreende, contudo, ao buscar prever o reconhecimento da pessoa do escritor também por meio da retórica, ao valer-se de seu instrumental de produção de discursos persuasivos para 
prover a interpretação do discurso privados das cartas. Propõe-se uma arte de conjecturar acerca da pessoa do escritor da carta, tanto de sua alma quanto de seu corpo, por meio dos modos de escrever e se exprimir, seja em termos dos caracteres (grafia, ortografia, pontuação), da escolha e forma lexical, da construção frasal e, por fim, do estilo, o qual conflui com os conceitos. Espera-se para isso a coerência entre o dito e o pensado, ao modo mais propriamente filosófico, do que apenas a produção de efeitos, por vezes a todo custo lógico, sobre o ouvinte a fim de conduzi-lo ou submetê-lo, atitude mais propriamente retórica.

Como veremos, a pessoa buscada nos escritos não diz respeito a um indivíduo isolado apenas, mas também a um habitante de uma região (reconhecido pelas marcas dialetais da escrita), que compartilharia com outros características semelhantes. Inicialmente, porém, Baldi parte de uma série de testemunhos de autoridades antigas sobre a possibilidade de a alma ser exposta pelas palavras.

Assim, no capítulo I, é aduzida uma passagem do pseudo-Demétrio que vê na carta entre amigos a exposição da "imagem da alma", citando em seguida outros autores antigos que também acreditavam que a fala ou a escrita exporiam a alma: Dionísio de Halicarnasso (em relação aos discursos de Lísias), Menandro (em relação às palavras), Sócrates eescritos bíblicos (em relação à fala), Aristóteles (em relação à fala e à escrita). Dos autores modernos, é citado apenas Pietro Vettori², que, segundo Baldi, teria afirmado que aquele que "lê uma carta imediatamente, se tem olhar agudo, vê o coração do escritor no meio do peito".

A correlação que se estabelece aqui é entre a fala e as ações que "demonstram os costumes e hábitos de cada um", de modo que a fala também é entendida enquanto ação - conhecimento certamente anterior ao estabelecimento das técnicas retóricas.

Contudo, no capítulo II, defende-se que esse tipo de interpretação não se estenderia a todos os tipos de escritos. As ressalvas de Baldi se iniciam com os escritos em verso, cujo ritmo obrigaria "o escritor a sair de seu ordinário e natural modo de falar", e se estenderia a certa prosa antiga e moderna, uma vez que "quiseram alguns antigos que a prosa do poeta fosse um pouco dessemelhante de quem a escrevia, fosse desigual, cheia e plena de epítetos e figuras pouco convenientes como se pode ver nos diálogos e nas prosas de alguns modernos". A seu ver, a alma do escritor também não se manifestaria certamente na prosa científica, na narrativa

${ }^{2}$ Ou Petrus Victorius (1495-1585), um dos principais divulgadores da cultura grega no período, tendo editado textos de Ésquilo, Eurípedes, a Retórica de Aristóteles, o Do estilo do pseudo-Demétrio, entre outros. 
histórica, na eloquência dos discursos (contrapondo-se ao citado Halicarnasso), nem nos diálogos e nas comédias (que trariam apenas o caráter das personagens).

No que diz respeito aos discursos, a refutação o contrapõe ainda a Quintiliano que em sua L'istituzione oratoria (livro XI, 1, 30) afirma: "Um discurso [oratio] faz conhecer quase sempre o caráter de quem o pronuncia e desvela os segredos da alma: não sem razão os gregos propagaram o dito: 'cada um, tal como vive, assim fala".

Para Baldi, porém, a carta privada restaria como único escrito no qual se poderia ver refletida uma imagem mais ajustada da alma do escritor. Os demais produtos letrados fariam como que o "espelho côncavo e convexo, um [fazendo] a coisa maior e o outro menor que o próprio ser".

Reiterando a distância da fala dos poetas, são relembrados do pseudoDemétrio os preceitos de uma escrita de carta clara e sem artifícios, estilo que confluiria com a tradicional imagem da familiaridade: clara e sem meandros. Entre outras considerações também é relembrada a necessidade da brevidadeapontada por Sêneca. Baldi, por fim, nota que essas considerações, ao serem tomadas como regras, não deixariam de igualmente dificultar o entendimento da natureza de quem escreve. Facilitaria esse entendimento, antes, um escrito "sem arte, sem erudição ou segunda intenção". E para se reconhecerem os "costumes" apresentados nessas cartas, recorrer-se-ia, contudo, a certa ordem retórica, observando-se:

1. o exórdio, que "prepara o ânimo do leitor para entender aquilo que se escreve", e provê os motivos do escrito;

2. a narração, que "exprime o que se quer";

3. a confirmação, espécie de reiteração do pedido para imprimir a vontade do escritor;

4. os caracteres, o modo e o estilo da escrita; os caracteres, "para uns, [compreenderiam] os elementos que compõem as palavras,as vírgulas, os pontos, os parênteses, a ordem, a posição e o arranjo desses elementos; para outros, a pureza da língua, a exatidão gramatical, a ortografia, o uso de palavras próprias ou metafóricas, e se as frases ou os períodos são figurados ou não" (BALDI, 1622/1992, p. 12).

Adverte-se, neste momento, que, independentemente dos vários tipos em que se subdividiriam as cartas (como as de pedido, recomendação, conselho e outras), elas não deixariam de manifestar as características de seus escritores, de modo que uma carta de recomendação de um soberbo seria diversa da de um modesto. Como se o comportamento vicioso não pudesse ser inteiramente dissimulado, algo que parece ter fundamento, 
já que comumente pessoas jactanciosas parecem considerar seu vício (excesso) senão uma virtude (ação razoável), ao menos um valor.

No capítulo III, ampliam-se as possibilidades de conhecimento de "vestígios" não só da alma mas também do corpo do escritor, isto é, se jovem, maduro ou velho.

Baldi pondera, então, que uma carta não chega a ser um espelho de todas as propriedades e pensamentos, seja pela arte que oculta, seja pela ocasião imprópria para exposição, pontuando que a conjectura feita a partir de uma carta teria de ser corroborada pelas demais. De uma carta se poderia conjecturar, por exemplo, se se trata de um jovem inexperiente quando se percebe "arrogância", ou ainda, se se trata de um ignorante e presumido quando expressa mal seu argumento.

São elencadas no capítulo IV as quatro qualidades que poderiam ser deduzidas do escritor da carta:

1) externas: se conhecido ou desconhecido, amigo ou inimigo, pobre ou rico, liberto ou escravo etc., e mesmo uma (algo estranha aqui) disposição momentânea;

2) do corpo: se de pouca conta, são, velho ou galhardo, homem ou mulher etc.;

3) do intelecto: mais facilmente se mostra se é judicioso, letrado, prudente, mentiroso, simulador, enganador etc.;

4) do apetite (temperamento): mais próximo do costume e hábito do escritor e que afeta a sua ação, como a alegria, o ardor, a crueldade, a indignação etc. (BALDI, 1622/1992, p. 19).

Reitera-se que esse conhecimento adviria de cartas escritas "sem máscara e artifício", quando os costumes são "claros", de modo que se possa chegar aos não manifestos.

O capítulo V traz cinco "instrumentos" por meio dos quais essas quatro qualidades do escritor desse tipo de cartas seriam verificadas:

1. do caractere, que compreende a figura ou o retrato da letra ou "elemento", e inclui a pontuação;

2. do vocábulo, que compreende o corpo ou a terminação dele, como por exemplo no uso de farraggio para farò pelo rei Enzo, o primeiro, segundo a nota da edição Studio Tesi, tratando-se de forma arcaica de futuro usada pelo referido rei da Sardenha ( 1220-72);

3. da frase ou locução: composição de palavras que compõem o período e os membros dele; podendo ser de quatro tipos: própria, metafórica, figurada e mista de todas; 
4. do estilo ou maneira de dizer, isto é, da estrutura ou forma da oração seguindo a classificação do pseudo-Demétrio: tênue, branda, grave e magnífica;

5. do conceito, entendido como o argumento e a coisa tratada (BALDI, 1622/1992, p. 21-22).

Finalmente, no capítulo VI, somos introduzidos ao método, ou antes às correlações que Baldi estabelece para as suas interpretações. Começando da grafia dos caracteres, quando são destacados os seguintes tipos de escrita:

(a) descuidada e com uma "pena muito calcada": pessoa de pouca perspicácia e muito dedicada aos prazeres, temperamento que se aproximaria do sanguíneo (instabilidade da mente e tagarelice) e do melancólico (preguiça);

(b) muito descuidada, desigual e de linhas tortas: predominância de inclinações naturais, cólera, desigualdade nas ações, próprio dos jovens;

(c) veloz e desigual: homem desigual nas ações e mesmo na fala, inoportuno, ambicioso e litigioso;

(d) veloz e igual e bem formada, parecendo deleitar-se com o escrever: homem que pouco sabe e pouco vale, imprudente e vaidoso, pois raros seriam os homens de bela escrita judiciosos e prudentes, sendo ainda frios, avaros, pródigos ou intemperantes, indiscretos, características associadas também aos jovens, e raro nas mulheres;

(e) feia mas inteligível: homem não jovem;

(f) de letras pequenas: homem de pouca visão, velho, ou de pouco espírito;

(g) de letras alongadas: jovem efeminado e vicioso (BALDI, 1622/1992, p. 23-25).

É interessante destacar ainda deste capítulo sua notação sobre a escrita elegante, a qual dependeria da imaginação: "uma vez que quem tem boa imaginação o mais das vezes não tem bom intelecto, segue que quem escreve bem valha muito menos de engenho e mente do que quem escreve mal". Uma formulação paradoxal para quem tem o hábito de correlacionar belas letras com capacidade argumentativa em termos lógicos, algo que se sabia então diferente, sendo sofistas e retóricos conhecidos por sua submissão da razão à beleza ou à habilidade persuasiva. Ponderação que será reposta no próximo capítulo, o sétimo, sobre a diversidade ortográfica e as pontuações. 
Baldi trata daqueles que apresentam má ortografia. O uso siciliano é dado como exemplo, pela troca de letras (alma > arma, parola [palavra] > palora), de modo que essas variações dialetais são vistas como erros que indicariam pessoas descuidadas, ignorantes, negligentes, pouco práticas. $\mathrm{O}$ negligente, mais especificamente, porém, se veria em sua variação de usos corretos e errados; o descuido também poderia ocorrer pela intimidade entre os correspondentes ou pelo pouco respeito, sendo então dado como exemplo Cícero em suas então famosas cartas a Ático, a quem pela amizade "era lícito proceder com pouco respeito". Apesar de esses erros poderem indicar pessoa pouco conhecedora de retórica, poética e ciências, Baldi adverte que se fossem acompanhados de "muitos sinais contrários" não seguiria a dedução acima, caso de Plotino "grandíssimo filósofo", ainda que pecasse na ortografia e na pontuação. Retoma-se aqui o argumento anterior, reputando justamente a um filósofo a possibilidade de descuido com aspectos algo menores da expressão escrita, isto obviamente quando não afetassem a argumentação.

Sobre a pontuação, escritos sem pontos (punti) e sinais de distinção (distintioni) ${ }^{3}$ revelariam um escritor "pouco entendedor ou pouco diligente, e se for negligentee não cuidar das coisas pequenas (pressuposto que as entenda), ou é pessoa de grande ânimo e de muito valor [caso de Plotino], ou sempre descuidada, pouco preocupada com a boa opinião", disposições que poderiam ser distinguidas pela compreensão do argumento, da coisa tratada. De outro lado, o bom uso de pontos e sinais de distinção mostraria um conhecedor e literato, que no "explicar seu argumento [seria] discreto, diligente e claro"; os pontos e os sinais de distinção sem propósito revelariam escritor pouco entendedor de letras, mas que quer mostrar saber mais, sendo pois confuso, duvidoso e ansioso.

É neste capítulo ainda que Baldi alerta que tais correlações não são automáticas, versando em torno do provável e do contingente, daí a arte que propõe se tratar de uma "arte conjectural"; relembrando corretamente que afirmações universais - no que diz respeito ao menos às ciências humanas, digamos - "não são nunca totalmente verdadeiras", já que costumam apagar as exceções.

3 Traduzidos na recente edição francesa por ponctuation e espacements du text, cf. BALDI, 1993, p.115. 
O capítulo VIII aborda os corpos dos vocábulos (voci), os quais explicitariam ainda mais a natureza do que os caracteres escritos (caratteri), podendo ser considerados quanto ao corpo ou à terminação (termine). Ao partir dos vocábulos que eram repassados à escrita, Baldi assinala a diversidade que "mostra a variedade da pátria", cujas regiões e cujos lugares tinham costumes próprios, os quais seriam manifestados pelo escritor. Lembremos aqui que a península itálica ainda não conhecia a padronização/nacionalização da língua oral/escrita, existindo o uso de termos dialetais também nos escritos. Assim, Baldi informa que os habitantes de Siena não usavam a letra " $z$ " preferindo escrever avessa em lugar de avezza (habituada), e os piemonteses escreviam altetta em lugar de altezza (altura). As diferenças de conduta dos habitantes de uma mesma região se manifestariam nas cartas de modo mais evidente pela forma das palavras, e seriam relacionadas com a teoria hipocrática dos quatro humores: quente e frio, úmido e seco.

Assim, por exemplo, entre outras diferenças, assinala-se uma divisão nos dialetos italianos entre os que usam menos consoantes, cujos usuários, tendo do úmido, seriam lentos nos discursos e nas ações, corretos e obedientes às leis, mas instáveis, volúveis e medianos nos negócios e excessivamente prudentes, "isto é com excesso de respeito" a beirar o temor, como "pareciam" os venezianos; ou ao contrário, os que têm presteza de língua, tendo do calor e da sequidão, seriam dispostos, ambiciosos e altaneiros, prontos à sedição e à discórdia se "a bondade das leis, a adquirida prudência e a razão que em muitos deles predomina não os regulasse", caso dos genoveses; e assim por diante.

Das palavras ascende-se à frase (cap. IX), a qual é dividida em três tipos: própria, metafórica e figurada. A primeira serviria para exposições de doutrinas, para o gênero deliberativo e para as narrativas; as duas últimas para os "outros dois gêneros [epidítico e judiciário] e para explicar conceitos que nascem do apetite irascível e concupiscível”. Das três nascendo um gênero misto, que a seu ver seria útil aos poetas e aos que pretendessem escrever "altamente". Características gerais, "nunca totalmente verdadeiras", mas que participam do imaginário que forja ou observa identidades, semelhanças ou identificações sociais.

Assim o uso de frases sem ornatos indicaria pessoa quieta e não apaixonada, "de meia idade, sem soberba e arrogância", comum aos "inferiores" eaos que requerem o objeto de seu desejo, sendo exemplificadas por Virgílio em suas narrativas.

O uso de metáforas é considerado mais revelador devido à maior similitude que pediriam em relação ao indivíduo, a qual é extraída das coisas próximas das que são o ofício (mestiere) de cada um, ocorrendo assim demonstrar o "ser, o exercício e a natureza das pessoas": 
(a) metáforas baixas e vis indicariam "escritor malcriado", jovem, sem filhos e esposa;

(b) se se escreve "poeticamente e de modo enfático", tem-se uma pessoa pouco judiciosa, sendo maneira própria dos amantes;

(c) os que utilizam alegorias e modo enigmático, "quando não sabem muito outro modo, são de intelecto turvo e confuso", sendo pessoas "obstinadas, indiscretas, desdenhosas e plenas de certo ódio e indignação em relação às pessoas que os tomam como grosseiros e pouco amáveis";

(d) os que usam metáforas comuns seriam discretos, judiciosos, práticos, perspicazes e igualmente ativos, não odiarão nem estarão dispostos a amar sem ocasião, serão civis mas antes avaros, por vezes dirão mentiras", terão desculpas, discutirão e por dinheiro estarão dispostos a ações pouco louváveis (BALDI, 1622/1992, p. 40-42).

As figuras são tratadas nos capítulos X e XI, sendo divididas em dois tipos: as de discurso (oratione), ou schemata, e as dos pensamentos (concetti), ou tropi. A diferença entre schemata e tropi não sendo clara.

Quintiliano (L'istituzione oratoria, livro IX, 1, 4 e 7) definiu tropo como uma "expressão [sermo] cujo significado foi transferido do natural e fundamental para outro", já uma figura seria uma conformação do discurso distante das expressões ordinárias e espontâneas [podendo] se realizar com palavras próprias e colocadas na ordem natural; contudo ele mesmo chegou a apontar que para muitos as figuras seriam o mesmo que tropos, sentenciando por fim, no mesmo livro (IX, 1, 7-8):

não importa de que modo sejam chamadas, se é claro qual vantagem derive ao discurso, e não são os vocábulos a mudar a natureza das coisas. Tal como os homens, se atribuem nome diverso do que tinham, restam os mesmos, assim essas coisas, sejam chamadas tropos ou figuras, produzirão o mesmo efeito; não ajudam pelos nomes, mas pelos efeitos.

Sobre as figuras do discurso, Baldi adverte inicialmente da pouca utilidade de algumas por serem muito comuns, como em "minha mulher e eu estou bem" (BALDI, 1622/1992, p. 43), ocorrendo zeugma ou silepse, ou seja uma concordância irregular. Ademais, nota que se as figuras são artifícios valorizados quando usados em outros escritos, especialmente os chamados poéticos, ao ocorrerem na carta privada denotariam antes defeitos do escritor.

Das figuras úteis, seguem os quadros abaixo; contudo, deve-se ter em conta, em acordo com a nota 60 da edição Studio Tesi, que a classificação de Baldi "é confusa e inexata", o que ocorre especialmente nos exemplos extraídos de Petrarca, os quais foram suprimidos aqui. 
224 - Remate de Males 35.1

FIGURAS DO DISCURSO (SCHEMATA $)^{4}$

Figura Definição/Função Tipo de escritor

\begin{tabular}{|c|c|c|}
\hline Epanodos & $\begin{array}{l}\text { [lat. regressio; retorno a um dos } \\
\text { principais membros da frase } \\
\text { provendo um detalhe, } S R \text { ] }\end{array}$ & $\begin{array}{l}\text { não artificiosamente, revela } \\
\text { pessoa de pouca memória, } \\
\text { tomada pelo afeto, sem atenção } \\
\text { ao que fala }\end{array}$ \\
\hline Paradiastole & $\begin{array}{l}\text { [separação e distinção de conceitos } \\
\text { semelhantes, e.g., falar sábio ao } \\
\text { invés de astuto. } I O, \mathrm{IX}, 3,65]\end{array}$ & \multirow{2}{*}{$\begin{array}{l}\text { afetado, quer fazer-se } \\
\text { engenhoso e literato, presumido } \\
\text { (gonfio) e de pouco juízo ao } \\
\text { utilizar este modo onde não } \\
\text { cabe }\end{array}$} \\
\hline Antífrase & $\begin{array}{l}\text { [Significação do contrário. IO, IX, } 2 \text {, } \\
47^{-8} \text { ] }\end{array}$ & \\
\hline Metalepse & $\begin{array}{l}\text { [lat. transumptio, } S R] \text { variação do } \\
\text { discurso, passando de uma coisa a } \\
\text { outra sem intermediação }\end{array}$ & \multirow[t]{2}{*}{$\begin{array}{l}\text { confuso, dá a entender de saber, } \\
\text { bobo e amante de si mesmo } \\
\text { mais do que devia }\end{array}$} \\
\hline Apostrofe & $\begin{array}{l}\text { [lat. aversio, } S R] \text { voltar-se a algo } \\
\text { diferente do que se fala }\end{array}$ & \\
\hline Silepse & $\begin{array}{l}\text { [lat. conceptio, SR; sintaxe de } \\
\text { concordância irregular, quando } \\
\text { dois sujeitos recebem um verbo no } \\
\text { singular] }\end{array}$ & \multirow[t]{2}{*}{$\begin{array}{l}\text { recebem menor censura, pois } \\
\text { mostram menor afetação } \\
\text { e vaidade, principalmente } \\
\text { quando parcas }\end{array}$} \\
\hline Prolepse & $\begin{array}{l}\text { [prevenir possíveis objeções. } I O \text {, IX, } \\
2,16]\end{array}$ & \\
\hline Hirmos & $\begin{array}{l}\text { ordem continuada da oração sob um } \\
\text { verbo [a prover ao final o sentido. } \\
I O, I X, 4,22]\end{array}$ & $\begin{array}{l}\text { quieto, de juízo mediano, logo } \\
\text { mansueto e benigno }\end{array}$ \\
\hline Antítese & [lat. contentio, $S R]$ contraposição & desdenhoso, mas perspicaz \\
\hline Topografia & [descrição de lugar, $S R$ ] & \multirow{2}{*}{$\begin{array}{l}\text { se poética, é vã e presumida se } \\
\text { imperfeita, de pouco juízo }\end{array}$} \\
\hline Cronologia & $\begin{array}{l}\text { [provavelmente chronographia; } \\
\text { descrição de uma circunstância } \\
\text { histórica, } S R \text { ] }\end{array}$ & \\
\hline Polissíndeto & $\begin{array}{l}\text { [abundância de conjunções. } I O \text {, IX, } \\
3,50]\end{array}$ & \multirow{2}{*}{$\begin{array}{l}\text { demonstram parte irascível, } \\
\text { indício de soberbo, presumido } \\
\text { e desdenhoso, pois exageram as } \\
\text { coisas que explicam }\end{array}$} \\
\hline Assíndeto & $\begin{array}{l}\text { [dissolutio, omissão de conjunções, } \\
\left.I O, \mathrm{IX}, 3,5^{\mathrm{O}}\right]\end{array}$ & \\
\hline
\end{tabular}

${ }^{4}$ Seguem entre colchetes complementações a partir da Silva Rhetoricae (SR) e da L’istituzione oratoria $(I O)$ de Quintilian 


\begin{tabular}{|c|c|c|}
\hline Aposiopese & $\begin{array}{l}\text { [lat. reticentia, interrupção: mostra } \\
\text { certo afeto ou antes certa ira... ou } \\
\text { certa apreensão e quase escrúpulo. } \\
I O,[X, 2,54]\end{array}$ & \multirow[t]{2}{*}{$\begin{array}{l}\text { nasce de ignorância, ou de } \\
\text { muito desdém ou vergonha }\end{array}$} \\
\hline Hipálage & atribuir a um o que é de outro & \\
\hline $\begin{array}{l}\text { Imprecação, } \\
\text { Execração }\end{array}$ & & ânimo perturbado \\
\hline $\begin{array}{l}\text { Rimas na } \\
\text { prosa }\end{array}$ & $\begin{array}{l}\text { [homoioteleuta, finais de frases } \\
\text { iguais] }\end{array}$ & \multirow[t]{2}{*}{$\begin{array}{l}\text { tem do bufão; obra da potência } \\
\text { concupiscível }\end{array}$} \\
\hline Paronomasia & jogo de palavras [bisticcio] & \\
\hline Prosopopeia & $\begin{array}{l}\text { [diálogo imaginário entre coisas ou } \\
\text { pessoas. IO, livro IX, 2, 29-37] }\end{array}$ & sem juízo; a ser evitada \\
\hline $\begin{array}{l}\text { Dubitatio } \\
\text { Diaporesis }\end{array}$ & $\begin{array}{l}\text { responder a objeções tácitas, } \\
\text { derrisões e interrogações }\end{array}$ & \multirow[t]{2}{*}{$\begin{array}{l}\text { indício de inoportuna } \\
\text { perturbação da mente, depessoa } \\
\text { apaixonada e pouco contente, } \\
\text { de idiotas e irresolutos; mas } \\
\text { esplendorosas se usadas a } \\
\text { propósito }\end{array}$} \\
\hline Dialogismo & $\begin{array}{l}\text { [discursos imaginários entre } \\
\text { homens, diálogoi, sermocinatio. IO, } \\
\text { IX, 2, 32] }\end{array}$ & \\
\hline Barbarismo & $\begin{array}{l}\text { [erro no escrever ou falar uma } \\
\text { palavra. } I O, I, 6]\end{array}$ & \multirow[t]{2}{*}{ ignorância e pouco juízo } \\
\hline Solecismo & $\begin{array}{l}\text { [erros com mais palavras. } I O, I, 5 \text {, } \\
34 \text { ] }\end{array}$ & \\
\hline Acirologia & fala imprópria & $\begin{array}{l}\text { qualidade da ira e do amor } \\
\text { venéreo }\end{array}$ \\
\hline Parison & $\begin{array}{l}\text { [emprego de palavra não muito } \\
\text { diversa de outra, ou de igual número } \\
\text { de sílabas e mesma terminação. } I O \text {, } \\
\text { IX, 3, 75-76] }\end{array}$ & \multirow[t]{2}{*}{ próprio de pessoas enamoradas } \\
\hline Perissologia & $\begin{array}{l}\text { [perífrase inadequada. IO, VIII, 6, } \\
61 \text { ] }\end{array}$ & \\
\hline Anfibologia & [ambiguidade] & $\begin{array}{l}\text { não buscada, vem da ignorância, } \\
\text { do pouco juízo e do ser duvidoso; } \\
\text { buscada, resulta na elipse }\end{array}$ \\
\hline Perífrase & $\begin{array}{l}\text { descreve a coisa de modo mais longo } \\
\text { do que devia }\end{array}$ & tagarelas, vãos, arrogantes \\
\hline
\end{tabular}




\begin{tabular}{l|l|l}
\hline Tapeinosis & $\begin{array}{l}\text { [meiosis, diminutio, tipo de litotes, } \\
\text { vício da diminuição da grandeza ou } \\
\text { dignidade de uma coisa. IO, VIII, 3, } \\
48]\end{array}$ & $\begin{array}{l}\text { duvidoso, nocivo, injurioso, } \\
\text { desesperado, vil e presumido }\end{array}$ \\
\hline Litote & rebaixa as coisas & \\
\hline Cacofonia & $\begin{array}{l}\text { [produção de som de efeito } \\
\text { desagradável] }\end{array}$ & sem ouvido, sem juízo \\
\hline
\end{tabular}

Já os tropos, ou figuras de conceito, de pensamento, seriam as figuras que mais se aproximariam assim da alma, logo, mais revelariam a natureza do escritor.

FIGURAS DE PENSAMENTO (TROPI)

Figura Definição /Função

Tipo de escritor

\begin{tabular}{|c|c|c|}
\hline Paremia & motes agradáveis & $\begin{array}{l}\text { judicioso, perspicaz, discreto, } \\
\text { diligente, industrioso, melancólico e } \\
\text { magro; misericordioso mas invejoso }\end{array}$ \\
\hline Carientismo & adocica coisas ásperas & $\begin{array}{l}\text { modesto, agradável, amável, } \\
\text { discreto, cortês }\end{array}$ \\
\hline Comparações & & $\begin{array}{l}\text { não é razoável ter nobres } \\
\text { comparações na boca do populacho, } \\
\text { nas cartas e na fala comum; como } \\
\text { se deve, demonstra vivacidade } \\
\text { de engenho e prontidão da } \\
\text { imaginação; pode indicar coléricos } \\
\text { e melancólicos; espécie de vaidade } \\
\text { usá-la na fala familiar e nas cartas; } \\
\text { fala de professor }\end{array}$ \\
\hline Perífrase & $\begin{array}{l}\text { [usa mais palavras por uma só. } \\
I O, I X, 1,6]\end{array}$ & \multirow{2}{*}{$\begin{array}{l}\text { necessárias para coisas pouco } \\
\text { honestas e claras ou sem palavras } \\
\text { devidas; em outras ocasiões seu uso } \\
\text { denota pessoa pobre de palavras, } \\
\text { propriedade do melancólico que não } \\
\text { encontra o nome das coisas tanto } \\
\text { mais quanto mais precisa }\end{array}$} \\
\hline Catacrese & $\begin{array}{l}\text { [uso de palavra em significado } \\
\text { impróprio a coisas sem nome } \\
\text { próprio. } I O, \mathrm{VIII}, 6,34]\end{array}$ & \\
\hline Hipérbole & $\begin{array}{l}\text { [exagero geralmente } \\
\text { acompanhado de comparações } \\
\text { e metáforas, } S R \text { ] }\end{array}$ & $\begin{array}{l}\text { presumido, falador, ignorante, } \\
\text { mentiroso, adulador }\end{array}$ \\
\hline
\end{tabular}




\begin{tabular}{|c|c|c|}
\hline Parênteses & $\begin{array}{l}\text { [interrupção do discurso para } \\
\text { inserção de outro conceito. IO, } \\
\text { livro IX, 3, 23] }\end{array}$ & \multirow[t]{4}{*}{$\begin{array}{l}\text { juízo confuso e desordenado se } \\
\text { usados sem razão }\end{array}$} \\
\hline Hipérbato & $\begin{array}{l}\text { [transgressio; transporta uma } \\
\text { palavra ou parte dela do seu } \\
\text { lugar natural para outro. } I O \text {, IX, } \\
1,6]\end{array}$ & \\
\hline Síntese & $\begin{array}{l}\text { [A n. } 133 \text { da edição Studio Tesi } \\
\text { traz como correlato simploche, } \\
\text { figura de palavra consistente } \\
\text { na combinação de anáfora [...] } \\
\text { e epífora (repetição de uma } \\
\text { ou mais palavras no final dos } \\
\text { enunciados] }\end{array}$ & \\
\hline $\begin{array}{l}\text { Hysteron } \\
\text { proteron }\end{array}$ & $\begin{array}{l}\text { [posterior primeiro; inversão } \\
\text { temporal dos acontecimentos, } \\
S R]\end{array}$ & \\
\hline Ênfase & $\begin{array}{l}\text { [fazer entender mais do que se } \\
\text { disse. } I O, I X, 2,3]\end{array}$ & $\begin{array}{l}\text { pleno de afeto; se não requerida } \\
\text { pela matéria mostra escritor quente, } \\
\text { ousado, pronto, naturalmente } \\
\text { eloquente, sedicioso, apto a causar } \\
\text { tumultos }\end{array}$ \\
\hline Ícones & $\begin{array}{l}\text { [comparação de uma pessoa } \\
\text { com uma imagem, } S R \text { ] }\end{array}$ & \multirow[t]{2}{*}{$\begin{array}{l}\text { de raro uso na fala familiar; para } \\
\text { professores }\end{array}$} \\
\hline $\begin{array}{l}\text { Parábolas ou } \\
\text { paradigmas }\end{array}$ & $\begin{array}{l}\text { [paralelo entre coisas } \\
\text { dessemelhantes, especialmente } \\
\text { com propósito moral, SR] }\end{array}$ & \\
\hline $\begin{array}{l}\text { Apoteose ou } \\
\text { deificação }\end{array}$ & $\begin{array}{l}\text { Colocam-se as pessoas acima } \\
\text { das estrelas }\end{array}$ & $\begin{array}{l}\text { para mortos; para vivos é uso de } \\
\text { adulador, pessoa de pouco cérebro }\end{array}$ \\
\hline
\end{tabular}

Depois das figuras e dos tropos, Baldi passa a tratar do estilo (cap. XII), partindo da comparação entre a divisão tripartite de Cícero e a quadripartite do pseudo-Demétrio. Assim, ao estilo "alto" do primeiro corresponderia o "magnífico" do segundo, ao "baixo" o "tênue", e ao "médio" o "ornado" e o "grave".

- o estilo grave e claro indicaria escritor razoável, judicioso, literato, de bons modos, repleto de afeto e honesto, sendo próprio de magistrados;

- o obscuro revela alguém de poucas letras e juízo, tímido e vil, de sentimentos confusos;

- o humilde mostra homem sem paixões de amor e vaidade, mas também fraco (BALDI, 1622/1992, p. 54-55). 
As considerações sobre o modo humilde adentram o capítulo XIII, quando se previne do seu vício, a vileza, devido ou à coisa tratada quando o escritor não mostraria nem juízo nem costume louvável se não a apresenta em outros termos -, ou à qualidade da pessoa que escreve - quando o escritor mostra-se "homem de baixíssimo grau, sem juízo e saber, idiota e muito ordinário, muito sujeito ao afeto da ira, de alma baixa, sem ingenuidade e verdade" (id., p. 58).

O estilo implica a questão dos usos das palavras, de sua escolha e ordem que inicia o último capítulo.

Reconhece-se então haver maior facilidade para se conhecer a qualidade do escritor pelo conceito do que pela grafia, pelas palavras e pelas frases; definindo o conceito como composição ou divisão - talvez capacidade de argumentar sintética ou analiticamente -, ou ainda como "paixão da alma apta a explicar com palavras significativas ao ouvido", sendo "recolhido dentro do período" e delimitado por um ponto final. Alguns seriam próprios outros figurados. Como exemplo do próprio, a representar "a coisa como ela é", de modo "simples e sem arte", dá-se a seguinte sentença: "Pedro chora", cujo uso indicaria pessoa ingênua, modesta, quieta e de juízo. Já para o conceito figurado, quando se diz uma coisa e se entende outra, o exemplo é: "chovem as lágrimas do rosto de Pedro". Os conceitos expressos por palavras simples e "sem arte" indicariam ainda um "homem decoroso, modesto, judicioso, que não se preocupa com vãs honras nem opróbrio não merecido"; já conceitos "vulgares, triviais e populares raramente vêm de um espírito distinto"; raros seriam os "conceitos alegres em pessoas sofredoras"; e assim por diante.

Sobre a diferença entre frase e conceito não me parece haver muita clareza, pois porvezes entrecruzam-se, como no caso da simples afirmação. Para frase, Baldi já havia usado como sinônimos “período" e "locução", epara conceito pode-se entrever o sentido de pensamento, quando o equipara, no cap. V, a "argumento" e "coisa tratada" (id., p. 22). O Vocabolario della Crusca (1833, p.727), por sua vez, trazia várias acepções: entendimento, intenção, sentença, ideia concebida, opinião, pensamento, reputação, proposição, mente, ânimo, discurso, julgamento, motes argutos, ditos breves. Conceito sendo algo mais próximo do indivíduo que o concebe:

E talvez quem disse que a nossa linguagem [loquella] nos manifesta, muito mais teve olho à matéria e ao conceito do que às frases e aos vocábulos, e se estas imediatamente demonstram a pátria e o lugar onde se nasceu ou foi criado aquele que argumenta [ragiona], igualmente os conceitos demonstram quais sejam os hábitos [costumi] e paixões da alma daquela pessoa que fala [parla] (BALDI, 1622/1992, p. 63). 
Contudo, a diferença entre pessoas com o mesmo pensamento, opinião, conceito, se evidenciaria justamente pelo modo de dizer, de escolher as palavras e construir as frases:

\begin{abstract}
sebemduas [pessoas] tenham um mesmo pensamento e conceito em geral [universale], jamais porém em um mesmo modo e com as mesmas palavras e períodos serão visto a explicá-lo em particular, o que se vê claramente não só em dois escritores [autori] que da mesma coisa trataram, mas dois homens iletrados [idioti] e comuns [vulgari] que estiveram presentes ambos a um mesmo fato forem interrogados, jamais em um só modo apenas o contaram de modo que entre eles não se veja uma certa diversidade, pela qual se conheça que não foi um, mas foram dois que narraram [hanno recitato] aquele fato (id., p. 64).
\end{abstract}

Apesar de podermos, junto com Petrucci, criticar as limitações das correlações oferecidas por Baldi - reconhecidas pelo próprio autor, que no final cap. XIII convida os "homens judiciosos" a se aprofundarem na questão -, há que se notar que o corpus ao qual devem ser aplicados seus preceitos restringe-se ao das cartas privadas, e assim, pressupondo-se neste sentido a não necessidade das algo estáticas e esperadas máscaras institucionais, não há como deixar de notar um princípio lógico.

Erasmo de Roterdã, em seu De conscribendis epistolis, de 1522, após ter tratado das cartas que confluem com o conhecimento retórico, apresentou ao final as que escapavam até certo ponto dessa esfera: as cartas de informação, instrução, recomendação, agradecimento, congratulação, conciliação, obséquio e discussão, as quais teriam a mesma razão das cartas de lamentação para aparecerem entre as exceções, pois se tratava de classe "muito parecida com a de consolação, [na qual] nenhuma habilidade é necessária, já que a tristeza é apta a tornar qualquer um eloquente" (ERASMO, 1522/1985, p.236). De modo que a técnica de produção de efeitos não é esperada ou necessária sempre, havendo espaço para o espontâneo (porém, não desregrado).

Antes dele, Petrarca, em sua carta-prólogo ao seu epistolário Familiarium rerum libri (Livros de assuntos familiares) (séc. XIV/1991, p.7, §13), ao comentar suas próprias cartas, tendo-as revisado para reunilas, notou que a "eficácia" delas já estaria garantida pela própria amizade: "queres tanto bem aos teus amigos que te agradará o estilo daquele de quem estimas os afetos"; completando, então, ser uma inutilidade adornar-se para quem já agradamos; entendendo por fala adornada aquela que recorre a uma fala grandiloquente mais própria da retórica, seja em termos de discurso público, seja em termos de carta oficial.

Ao que parece, nem Petrarca, nem Erasmo, nem Baldi se deixaram submeter inteiramente ao artificialismo retórico eà teatralidade da vida de 
corte, reconhecendo que, apesar do conhecimento dos modos de produzir efeitos sobre o outro, havia espaço para a existência da exposição de si, ao menos entre prováveis e possíveis amigos.

\section{REFERÊNCIAS BIBLIOGRÁFICAS}

ARISTÓTELES. Fisiognomica. Trad. de Maria F. Ferrini. Milano: Bompiani, 2007.

ARISTÓTELES. On the Soul. Trad. de J. W. S. Hett. 6. ed. Cambridge: Harvard University Press, 1995.

BALDI, Camillo. Come da una lettera missiva si conoscano la natura e qualità dello scrittore. Pordenone: Edizioni Studio Tesi, 1992.

BALDI, Camillo. La lettre déchiffrée. Trad. de Anne-Marie Debet e Alessandro Fontana. Paris: Belles Lettres, 1993.

ERASMO. On the writing of letters. Trad. de Charles Fantazzi. In: Collected works of Erasmus. Toronto: Toronto Press. 1985. p.1-254.

FONTANA, Alessandro. Introduction. In: BALDI, C. La lettre déchiffrée. Trad. de Anne-Marie Debet e Alessandro Fontana. Paris: Belles Lettres, 1993. p. 9-73.

HIPÓCRATES. De l'art de la médecine. In: Traités d'Hippocrate: De la nature de l'homme, De l'ancienne médecine, Des humeurs, De l'art médical. T. I. Trad. de M. Le Chevalier de Mercy. Paris: Eberhart. 1823.

PETRARCA. Le familiari. Trad. de Ugo Dotti. Livro I. Roma: Archivio Guido Izzi. 1991.

PETRUCCI, Armando. Prefazione. In: BALDI, C. Come da una lettera missiva si conoscano la natura e qualità dello scrittore. Pordenone: Edizioni Studio Tesi, 1992. p.VIII-XII.

QUINTILIANO. L'istituzione oratoria. A cura di Rino Faranda e Piero Pecchiura. 2vs. Torino: UTET, 1979.

Silva Rhetoricae. Disponível em: <http://rhetoric.byu.edu/> .

Vocabolario della lingua italiana. T. I, p. I, Firenze: Apresso David Passigli, 1833. 